\title{
QUEEN'S
UNIVERSITY
BELFAST
}

\section{A systematic literature review of university technology transfer from a quadruple helix perspective: Towards a research agenda}

Miller, K., McAdam, R., \& McAdam, M. (2016). A systematic literature review of university technology transfer from a quadruple helix perspective: Towards a research agenda. $R \& D$ Management. https://doi.org/10.1111/radm.12228

Published in:

R \& D Management

Document Version:

Peer reviewed version

Queen's University Belfast - Research Portal:

Link to publication record in Queen's University Belfast Research Portal

\section{Publisher rights}

(c) 2016 RADMA and John Wiley \& Sons Ltd

This is the peer reviewed version of the following article: Miller, K., McAdam, R. and McAdam, M. (2016), A systematic literature review of university technology transfer from a quadruple helix perspective: toward a research agenda. R\&D Management, which has been published in final form at http://onlinelibrary.wiley.com/wol1/doi/10.1111/radm.12228/abstract. This article may be used for non-commercial purposes in accordance with Wiley Terms and Conditions for Self-Archiving.

\section{General rights}

Copyright for the publications made accessible via the Queen's University Belfast Research Portal is retained by the author(s) and / or other copyright owners and it is a condition of accessing these publications that users recognise and abide by the legal requirements associated with these rights.

\section{Take down policy}

The Research Portal is Queen's institutional repository that provides access to Queen's research output. Every effort has been made to ensure that content in the Research Portal does not infringe any person's rights, or applicable UK laws. If you discover content in the Research Portal that you believe breaches copyright or violates any law, please contact openaccess@qub.ac.uk. 
Forthcoming R\&D Management

\title{
A Systematic Literature Review of University Technology Transfer from a Quadruple Helix perspective: Towards a research agenda
}

\begin{abstract}
Within recent years, there has been a rapid expansion of the University's role in economic development. This has resulted in University Technology Transfer (UTT) taking place within an increasingly complex network of regional stakeholders. This complexity has resulted in quadruple helix models where the triple helix model of academia, industry and regional government now includes societal based innovation users as a fourth helix. Despite this development, extant research is fragmented and lacks coherent frameworks and conceptualisations which fully depict the dynamic and evolving nature of UTT. Accordingly, this paper reviews Mode 2 UTT from a quadruple helix perspective to identify key themes to develop a research agenda which reflects progression from a triple into a quadruple helix ecosystem.
\end{abstract}

Keywords: Systematic Literature Review; Quadruple Helix; University Technology Transfer; Triple Helix; Technology Commercialisation; End Users

\subsection{Introduction}

Collaboration between government, academia and industry is considered to be of critical importance in University Technology Transfer (UTT) in enhancing regional economic and social development (Klofsten et al., 2010; Urbano and Guerrero, 2013); with the interplay between these three institutional spheres forming the crux of the well-established Triple Helix Model of UTT (Etzkowitz and Leydesdorff, 2000). However, in recent years, the effectiveness of this model has been questioned, as regions have failed to meet expected levels of UTT in terms of innovation, GDP and employment (Asheim and Coenen, 2005; McAdam et al., 
2012). In order to address this challenge, recent policy initiatives identify the need for more open and co-creational UTT involving societal based innovation user stakeholders leading to a complex network of quadruple helix stakeholders involved at various stages throughout the UTT process (Wilson, 2012; RIS, 2014). The inclusion of the fourth helix depicting societal based innovation users (Leydesdorff, 2011; Carayannis et al., 2012) and the subsequent emergence of quadruple helix structures reflect Bozeman et al.'s (2015) review demonstrating the increasing importance placed on public valued or societal led UTT.

Despite this, current UTT theory lacks coherent frameworks and conceptualisations which fully depict this evolving nature of quadruple helix theory and resulting structures. Whilst comprehensive literature reviews have been conducted, to date (Bozeman, 2000; O'Shea et al., 2005; Djokovic and Souitaris, 2008; Rothaermel et al., 2007) they tend to focus on a particular aspect of UTT and fail to fully encapsulate the dynamic and evolving nature of UTT which is embedded in an increasingly complex network of stakeholders innovation-user stakeholders seeking to influence the development of UTT in addition to that of receiving innovation outcomes. In fact, no reviews to date have explored the impact quadruple helix on UTT.

Given the wide and expanding scope of UTT, it is necessary in the first instance to define what is meant by UTT within criteria based limits to guide this literature review. Etzkowitz and Leydesdorff (2000: 118) argue that UTT can defined based on Gibbons et al. (1994) Mode 1 and Mode 2 theory of knowledge production as shown in Figure 1.

[Insert figure 1 here]

Using Mitev and Venters (2009) and Swan et al.'s (2010) interpretation in a UTT context, Mode 1 UTT refers to the traditional role of Universities in developing basic research leading 
Forthcoming R\&D Management

to societal learning and education. Mode 2 UTT, the focus of this paper, refers to Universities' newer role in UTT activities leading to the commercialisation of technology. Building on this, Hughes and Kitson (2012), Abreu et al. (2009) and Carayannis and Campbell (2009) refer to idea of Mode 3 which encapsulates University knowledge exchange involving a wide range of University - community knowledge exchange including training and development.Mode 2 UTT is distinguishable from traditional research in Universities (Mode 1), due to its relevance to practice (Starkey and Madan, 2001) or the context of application (Tranfield and Starkey, 1998). Consistent with Gibbons et al.'s (1994) definition of "Mode 2" knowledge production (i.e. Figure 1), Universities are seen as key actors or organisations in national innovation systems. Within such systems, universities are vehicles for technology transfer and a conduit through which knowledge exchange is made more effective (Cao et al., 2009). Resultant entities include, in addition to IP, licensing, patenting, spin-out companies and spin-in companies into university incubators and other technology bridge foundations or intermediaries (Bercovitz and Feldman, 2006) which support the codification and commercialisation of knowledge in the university context for commercialisation purposes (Rademakers, 2005). Further maturation of such entities may result in expansion and growth leading to relocation in University or Government Science Parks. Throughout the paper we adopt the term 'Mode 2 UTT' as referring to University based Mode 2 knowledge production through UTT with a view towards commercialisation.

To enhance coherence between recent policy and practice, the aim of this paper is to critically review Mode 2 UTT from a quadruple helix perspective and to identify key themes and future research agendas. The next section will discuss the systematic literature review (SLR) methodology followed. The core findings will then be presented from which four key themes are delineated. These themes are then synthesised and future research agendas are suggested. 
Forthcoming R\&D Management

\subsection{Review Methodology}

The methodology incorporated a SLR of double-blind peer-reviewed academic journal articles relating to the progression of UTT from a relatively closed system, to a triple helix and then on to a quadruple helix context. The importance of a structured and multiple-stage system for reviewing a large volume of academic literature is well acknowledged and as a consequence was deemed appropriate given the aim of this paper (Thorpe et al., 2005; Pittaway and Cope, 2007). The adoption of SLR proved instrumental in developing a robust and holistic collation of the developments of UTT over the past 34 years (i.e. since the introduction of the BayhDole Act). Details of the Five Stage SLR followed are given below.

\section{Stage 1: Keyword search}

Research on Mode 2 UTT is voluminous and multidisciplinary (Carayannis and Campbell, 2009). Thus, in order to define the boundaries of the subject, recognised experts in the area namely academics, technology transfer office staff and principal investigators were consulted to identify suitable keyword search terms.

Since the focus of this paper is Mode 2 UTT from a quadruple helix perspective, it was deemed appropriate to use all-encompassing search terms to initially review the topic in a holistic manner rather than taking each stage as an individual component. This approach resulted in five core search terms deemed valid by the experts consulted, namely "technology commercialisation and universities", "technology-based entrepreneurship and universities", "academic enterprise and universities", "Triple Helix and universities" and "Quadruple Helix and universities". 
Forthcoming R\&D Management

\section{Stage 2: Database Search}

Two distinct academic databases were utilised in order to cross-reference the results and eliminate the risk of disregarding relevant literature. The first search session was conducted through the 'ABI/Inform' database. ABI/Inform was chosen as the primary database on account of it offering a comprehensive and wide range of academic entrepreneurship and university commercialisation literature, in addition to its frequent use in systematic literature reviews (e.g. Becheikh et al., 2006; Djokovic and Souitaris, 2008). Once this initial search was completed, it was then repeated using 'Business Source Premier' database which has also been used frequently in systematic literature reviews is the industry's most frequently used research database (e.g. Pittaway et al., 2004; Djokovic and Souitaris, 2008). For each search, the keywords from Stage 1 were constructed into search strings which included a combination of an article title search. In order to be included, the article had to be published in a peer reviewed journal between 1980 and 2015. The sample size at this stage was 957 articles.

\section{Stage 3: Article Scan / Selection}

The aim of stage three was to refine the sample identified in stage two to ensure the inclusion of the most relevant articles. This consisted of three steps, the first of which was to eliminate any overlapping articles between the databases which reduced the sample size to 457 articles. Second, the abstracts of these remaining articles were read to determine their relevance given our research aim. Out of these 457 articles, 162 articles were downloaded, saved and labelled in a designated folder (labelled according to author and year of publication) as being potentially relevant to this literature review. Third, the bibliographical data of each paper was exported directly into Refworks for potential future referencing. Table 1 presents the number of papers selected in relation to each search term.

[Insert Table 1 here] 
Forthcoming R\&D Management

\section{Stage 4: Data Extraction}

The fourth stage was data extraction. The aim of this stage was to minimize researcher subjectivity. A standardised data extraction process (Tranfield et al., 2003) by means of a proforma form was conducted. The protocol involved recording the journal, author(s), title, year published, geographical area, research problem/question, theory base, paper type (descriptive/explanatory/conceptual), methodological approach, data sources, sample type, sample size, dependent variable (quantitative studies only), analysis, key findings/contributions, any need for further research and a section for recording any additional comments the reviewer had of the paper. This protocol was carried out for all 151 articles which resulted in a final document of 210 pages (on average 1.5 pages of single spaced data was extracted for each article). This document provided a raw data repository of the selected articles.

\section{Stage 5: Data Analysis}

The last stage involved importing all the relevant articles into NVivo 10 to conduct a process of open inductive coding (Miles and Huberman, 1994). Each article was opened in turn and read through NVivo $10^{1}$. The articles were then coded into free nodes and grouped into tree nodes (representing open codes and themes/subthemes). To ensure rigor and to increase the reliability of the coding process, the coding of data was conducted independently by two of the research teams with any variances in the codes discussed until a consensus was achieved. If a consensus could not be achieved, the third member of the research team was consulted.

\footnotetext{
${ }^{1}$ NVivo 10 is a software tool used to support qualitative and mixed methods research.
} 
Forthcoming R\&D Management

\subsection{Contextual Background -The emergence of the UTT quadruple helix model.}

In order to aid contextualisation of the SLR and to add meaning to the themes presented in section 4 , a trajectory of UTT spanning 30 years illustrating the antecedents which lead to the emergence the UTT quadruple helix model is presented in Figure 2.

[Insert Figure 2 here]

It is clear from the SLR that over the past three decades, collaboration between university, government and industry has evolved considerably (Etzkowitz and Leydesdorff, 2000; Miller et al., 2014). This evolution is in part due to a combination of globalisation and regionalisation in economic development (McAdam et al., 2012) with increased pressure from government on universities to take a more proactive role in regional and societal development (Rothaermel et al., 2007; Grimaldi et al., 2011). It is evident that the UTT Triple Helix Model is essentially an innovation-push model where innovation is seen as originating in academia, for example from technology disclosure, leading to the development of technology (Bercovitz and Feldman, 2006; Etzokowitz and Klofsten, 2005) aided by Government funding support and Industry (private sector) investment. Resultant entities such as spin out companies then seek out potential markets and customers for the technology-based products thus creating the innovation push effect within the Triple Helix model as identified by Gunasekara (2006). However, this innovation push model of Mode 2 UTT has been increasingly critiqued as failing to produce expected results in terms of increased innovation, GDP and job creation due to its lack of societal based innovation-user involvement (Asheim and Coenen, 2005; Edvardsson et al., 2011; McAdam et al, 2012). Furthermore, Scholtes, (2013) and Prajapati et al., (2013) refer to the excessive development costs and cycle times due to the closed nature of the process. $\mathrm{h}$ 
In acknowledgment of this, studies from the mid 2000's onwards refer to the increased pressure from government on Universities to seek and secure funding from non-Government sources leading to a heightened focus on Mode 2 UTT as a revenue stream for Universities (Lipinski et al., 2013). This required and subsequently resulted in closer interaction with regional stakeholders. Whilst the role of an 'extended peer user community' in technology commercialisation for disciplines such as biotechnology and nanotechnology has been noted since the early 2000's (Ivanova, 2014), it was not until 2009 that Carayannis and Campbell posited a quadruple helix innovation system, with "societal based innovation users" more fully integrated into the innovation processes as both innovation users and as influencing the Mode 2 UTT process at all stages of development. The inclusion of the fourth helix reflects the development and increasing complexity and change of modern economic systems which suggests that the triple helix is not sufficient to ensure long term sustainable growth (MacGregor et al., 2010; Ivanova, 2014). Figure 3 presents the transition from triple to quadruple helix structures.

\section{[Insert figure 3 here]}

The inclusion of this fourth helix challenges Mode 2 UTT in a number of ways. First, societal based innovation users are seen as potentially being involved in a co-creational manner throughout the Mode 2 UTT process rather than simply being passive end recipients (Edvardsson et al., 2011; Chesbrough, 2011). Thus, they create an innovation-pull effect within UTT. Second, they are defined also as stakeholders reflecting their committed involvement and mutual influence and participation throughout the UTT process. Third, they are representative of societal need and thus can increase the relevance of UTT and a University within a regional setting (Carayannis et al., 2012; Chesbrough, 2007 and 2010; Miller et al, 2014). Fourth, the user involvement suggests an open innovation approach where knowledge from multiple 
stakeholders is exchanged throughout the UTT process rather than the more closed Triple Helix approach (Johnston et al., 2010). Kenney and Mowery (2014), Arnkil et al., (2010) and Cooke (2005) suggest that from an Open Innovation perspective, the normative and primarily closed innovation Triple Helix-based knowledge transfer process adds to internalisation rather than exploring more diverse forms of knowledge as sources of innovation (Cooke, 2005; Carayannis and Rakhmatullin, 2014). Fifth, the closed innovation approach to UTT commercialisation is becoming prohibitively expensive and hence knowledge from societal based innovation user stakeholders becomes more attractive (Savva and Scholtes, 2013) leading to potentially shorter development cycle times (Prajapati et. al., 2013).

2009 onwards witnessed an increasing number of articles exploring the emergence of the quadruple helix however these articles largely undertake a macro perspective which emphasises that the quadruple helix is an agenda largely driven from the top down with limited research exploring the impact of quadruple helix structures on the Mode 2 UTT process. For example, Schoonmaker and Carayannis's (2013) study identify that most universities operating within a regional network appear to be still operating within triple helix structures despite national government innovation policy stressing the need to develop collaborative entities with societal based innovation users to produce more market relevant technology based products. However, it was noted that a small minority of firms show signs of operating within quadruple helix structures identifying a filtering down to Mode 2 UTT process levels. A study by MacGregor et al., (2010) looked at the Quadruple Helix readiness of 16 European cities and identifies that challenges lie at both a regional and sector level. Science-based industry sectors were identified as 'quadruple helix ready' due to their research departments and absorptive capacity which aid the bridging of basic research from universities (Mode 1) into their innovation processes (Mode 2). However, it was identified that regions with a dominance of companies in less technology intensive areas often innovate in-house in a closed manner and 
are less likely to have the required absorptive capacity or motivation to collaborate with universities. Carayannis and Rakhmaullin (2014) identify that variances across regions promotes quadruple helix structures where there is a need to formulate smart specialisation platforms in order to promote engagement between institutions to build on regional strengths. In this context, Smart Specialisation refers to regions within Europe specialising in specific technologies that have regional relevance and hence exerts an innovation pull influence on the Mode 2 UTT process consistent with the Quadruple Helix model. In sum, it is evident that despite the limited studies exploring quadruple helix to date, it is emergent in nature which is going to have profound effects on Mode 2 UTT and raises challenges which need to be identified and addressed to aid its development. Overall, Schuurman et al., (2012); Ivanova, (2014); Arnkil et al., (2010) and Carayannis and Rakhmatulin (2014) suggest the emergence of the quadruple helix model challenges the approach to UTT and Mode 2 UTT in particular, moving to a more complex and open based view of innovation involving the two way involvement of influencing stakeholders throughout all stages of the Mode 2 UTT process Thus, it is evident that the implications of the emergence of the quadruple helix is of sufficient importance as to warrant a critique of the existing Mode 2 UTT literature from a quadruple helix perspective to show key themes and research agendas.

\subsection{Key Emergent Themes}

The SLR literature review led to four main themes being identified as being critical to understanding the impact that the emergence quadruple helix structures has had on UTT which provides the basis for future research agendas. These findings in relation to each theme are shown in sub sections $(4.1-4.4)$. 
Forthcoming R\&D Management

\subsection{Theme 1: Tension between basic research and commercialisation}

An emergent key theme which has implications for the transition from a triple to quadruple helix models within Mode 2 UTT relates to the tensions arising between the various stakeholders which are now more complex with the addition of societal based innovation users and their involvement in the UTT process. The literature suggests that there is a need to identify and manage these tensions to help advance UTT research and practice agendas (Hughes and Kitson, 2012; Al-Mubaraki et al., 2013). According to the Lambert's Report (HM Treasury, 2003: 14) "companies and universities are not natural partners". This lack of affinity has resulted in tension and conflict throughout the history and process of UTT (Larsen, 2011) which is likely to increase in a quadruple helix context due to the increased involvement of the societal based stakeholders often with diverse agendas. Prior attempts to minimise such tension and conflict have resulted in legislation, the most significant being the Bayh-Dole Act (1980) in the USA, which as mentioned, created opportunities for Academic Entrepreneurs to benefit from their IP, patenting and licensing. However, critics including Goldfard and Henrekson (2003) acknowledge that the technology push implicit in the Bayh-Dole Act may lead to limitations in commercial viability of spin-out firm's products due to a lack of initial, or at least delayed emphasis on market pull and an over-reliance on technology push. This may have implications on the objectives of academics versus those of societal based innovation users as represented in the quadruple helix model where market pull is increased.

A significant empirical study by Larsen (2011) notes that a disincentive to would-be academic entrepreneurs is that basic research is often more cited than applied research, where citations is a mark of academic esteem. For example, Ambos et al. (2008) and Huyghe et al. (2014) suggest that this tension is manifested at an individual level with the academic having difficulty in reconciling these polarities ultimately requiring separate or ambidextrous structures and 
career paths as Mode 2 UTT becomes increasingly complex due to quadruple helix model influences. Bercovitz and Feldman's (2008) and Link and Siegel's (2005) identify that resolving the tension depends on local social factors such as training and culture and incentives related to UTT especially in times of significant change such as in the emergence of the quadruple helix model. O'Shea et al. (2008) echo this challenge and stress that there are substantial differences in an individual academic's ability to publish and engage in academic enterprise with a range of stakeholders, as is the case in the Quadruple Helix Model, with only a limited number being capable of successfully operating across the divide. Stokes (1997) suggests that these tensions can be shown in a classification with axes of fundamental understanding versus consideration of use. Building on Stokes quadrant analysis, Larsen (2011) suggests the need for Universities to dynamically shift towards Pasteur's quadrant i.e. maximising both fundamental knowledge contribution and societal use as stressed in the quadruple helix model. Furthermore, Clausen and Korneliusse (2012) suggest that senior management should recognise and drive this process at a Mode 2 UTT level by setting effective strategy and incentives, where the context is likely to be unique for each University due to variations in societal based innovation user stakeholders with diverse Smart Specialisation regional strategies, with a contingent, rather than best practice Mode 2 UTT approach necessitated.

Overall, the emergence of the quadruple helix structure with societal based innovation user stakeholders is likely to further highlight the tension between basic and applied research with the need for further significant allocation of resources to meaningfully progress the increased management demands of operating a Mode 2 UTT quadruple helix model. 
Forthcoming R\&D Management

\subsection{Theme 2: Developing Stakeholder Relationships}

A considerable amount of the Mode 2 UTT literature to date, relates to a mechanistic sciencebased technology push approach to technology development, however Colapinto and Porlezza (2012) identify that a quadruple helix system depends on not only 'hard' infrastructures but that the 'soft infrastructures' based on societal based innovation user stakeholder interactions (networking, knowledge transfer, human capital) are just, if not more important. Payumo et al.'s (2012) University case analysis suggests that Mode 2 UTT consists of bundles of policies which depend upon people interactions and partnerships. These tacit people-based UTT conduits can also lead to risk and uncertainty due to cultural and institutional bias across diverse stakeholders which ultimately limit UTT effectiveness especially where a wider range of societal stakeholders are involved as in the quadruple helix model (Lee, 2012).

Hidalgo and Albors (2008) and Plewa et al., (2013) note that a core element of the Mode 2 UTT processes, especially in a quadruple helix context, is the ability to manage stakeholder relationships strategically. Miller et al., (2014) and McAdam et al., (2012) apply stakeholder theory to explore the transitioning entrepreneurial university and identify that this increasingly open process raises issues in relation to the ability to manage multiple stakeholders objectives and often competing interests in a Mode 2 UTT quadruple helix setting. In particular, these studies identify that power resource relationships exist with UTT stakeholders whereby stakeholders will use withholding or usage strategies in order to exert their salience and achieve their own objectives. These may conflict with academic stakeholders whose agendas are more focussed primarily on obtaining resources to carry out research rather than on commercialisation as identified by Perkmann et al. (2013). Whilst the influence multiple stakeholders have on UTT is not new, this has only been discussed in a passive nature (Hidalgo and Albors, 2008). 
It is noted within the literature that quadruple stakeholder groups encapsulate stakeholders which are both regional (Todtling and Trippl, 2005; Ivanova, 2014) and organisational (i.e. organisational type) (Van Looy et al., 2011; Hewitt-Dundas, 2012) specific. Whilst core UTT activities and structural mechanisms across universities and regions may look similar, Galbraith and McAdam (2013) note that the interaction and relationships between these diverse stakeholders in a Quadruple Helix setting as a result of contextual factors will vary and may significantly affect UTT outcomes.

One of the most important people based aspects for a functioning quadruple helix is the quality of academic entrepreneurs (MacGregor et al., 2010; Miller et al., 2014). Extant research identifies that there are multiple, often conflicting demands on the academic entrepreneur's time (Perkmann et al., 2013). Given the considerable distance between typical industry and academic knowledge frontiers, i.e. between academics and societal based innovation user stakeholders, significant effort is required in coordination (Rothaermel et al., 2007; Perkmann and Walsh, 2007; Kotha et al., 2012). The academic or Principal Investigator (PI) is a core component in the UTT process and whilst all academics possess expert knowledge in their area, many academics vary in relation to their entrepreneurial attitudes and ability to engage with a wider range of stakeholders in the quadruple helix setting (Bozeman, 2000; Clarysse et al., 2011; Urbano and Guerrero, 2013). Indeed, Perkmann et al. (2013) identify that engagement with industry and societal based end users is reliant upon individual characteristics of academics such as demographics, career trajectory, productivity and motivation. Furthermore, organisational factors such as technology transfer support, formal incentives, department quality and department climate may impact upon willingness and ability of academics to engage with industry and end users. 
Forthcoming R\&D Management

In sum, university polices and structures need to encourage the engagement of quadruple helix stakeholders in Mode 2 UTT, with a recognition that engagement levels will vary across university types. Furthermore, it is evident that many academics still do not possess the skills, ability and motivation to network and interact effectively with societal based innovation users in a co-creational manner (MacGregor et al., 2010; Miller et al., 2014) which may hinder the realisation of quadruple helix implementation in Mode 2 UTT settings.

\subsection{Theme 3: UTT Performance Measures and Entities}

Mode 2 UTT performance measures have mainly focused on the output of entities such as patents, licenses, spin-outs, job creation (Payumo et al., 2012; Al-Mubaraki et al., 2013). However, Tello et al. (2011) suggest that these limited UTT performance measures can instil a bounded rationality, especially in the more open innovation pull setting of the Quadruple Helix model. Campbell et al. (2004) suggest that UTT performance measurements are emergent in nature as a result of on-going change in the external environment and that many measures are not adequately recorded such as tacit based activity costs and effectiveness which are significant when universities are operating within complex stakeholder relationships as in the quadruple helix context (Carayannis and Campbell, 2014). However, Grimaldi et al., (2011) and Clausen and Korneliussen (2012) suggest that contextual performance measures such as institutional and geographic factors involving regional stakeholders as societal based innovation users (Hayter, 2013) are required as opposed to a "one size fit all" approach. Moreover, Hughes and Kitson (2012) suggest that performance measurement in UTT (in addressing both Mode 2 and Mode 3 UTT) should consider constraints by scientific discipline: Health Sciences (culture); Science, Technology, Engineering and Maths (STEM) (costs, resources, partner identification, agreement on IP), Arts and Humanities (lack of time, rewards and poor marketing) and Social Sciences (bureaucratic, lack of resources, timescales, lack of 
experience and culture). These constraints may impinge on the ability of certain disciplines to fully integrate societal based innovation users in quadruple helix contexts into their UTT processes which supports research by MacGregor et al., (2010) who question certain region's readiness for the quadruple helix depending on industry sector predominance.

A reoccurring theme in Mode 2 UTT performance measurement throughout the literature is the challenges surrounding IP which is made more complex in a quadruple helix context when multiple stakeholders are collaborating. Larsen (2011) suggests that IP may actually limit openness and publishing by academic entrepreneurs as the IP patenting process can take considerable time in comparison to fast moving scientific fields. This need for protection may contrast with the 'first mover' strategy of a societal based innovation user. Moreover, the complexity and legal aspects of IP usually require in-house or external experts, and are beyond the current expertise of academic entrepreneurs. In some cases, Patent-based Investment Funds (PBIFs) are established (Gredel et al., 2012), which essentially commoditize patents as investments (Lee, 2012) where Galbraith and McAdam (2011:4) suggest that "mini ebays for technology and IP" are created. Larsen (2011) suggest that patenting is only a small part of Mode 2 UTT and its measurability (e.g. invention disclosures, number of patent applications, domestic patents granted) obscures other important Mode 2 UTT measures arising from managing quadruple helix based stakeholder interactions such as societal impact. There has been a trend towards 'easy access IP' for certain technologies to be exploited to have benefit to society and the economy however, many universities policies still require IP to be protected which will cause challenges when engaging in more co-creational Mode 2 UTT with industry and societal based end users.

An emergent field over the last five years relates to the emergence of entities referred to as intermediaries for Mode 2 UTT (Roxas et al., 2011; Gredel et al., 2012). Etzkowitz (2003) 
suggests that intermediaries often form at the interface of key junctures within the UTT process where Lee (2012: 1569) suggests they obscure these boundaries in a positive manner to improve connections, integration and knowledge transfer between stakeholders such as industry and societal based innovation users. Thus they are "bounded knowledge commons" involving networks from across UTT interfaces, interacting in a co-creational manner to increase Mode 2 UTT and thus are consistent with the Quadruple Helix model.

Hindle and Yencken (2004) suggest that intermediaries reflect entrepreneurship within Mode 2 UTT in that an entrepreneur can be viewed as an "in-between taker" i.e. availing of interface and cross boundary opportunities created by the inclusion of societal based innovation users. Examples of intermediaries entities and evidence of embracing the role of societal based innovation users in Mode 2 UTT is seen in Almirall and Wareham's (2011) study of Living Labs where pre-commercial procurement with early user involvement was found to advance technology development at early or pre-incubation stages of the UTT process in an innovation pull manner consistent with the quadruple innovation model. Almirall and Wareham (2011) identify processes of knowledge sensing and early prototyping in covering tacit, experiential and domain based knowledge (i.e. adding knowledge codification on the tacit-explicit knowledge continuum). Moreover, they suggest that living labs help to obtain critical mass for product creation within the UTT process through co-creational inputs from a diverse range of societal based innovation users throughout the Mode 2 UTT process stages. Another example of intermediary Mode 2 UTT entities is that of platform formation (Gredel et al., 2012). Typical examples are technology trading platforms and integrated project management platforms which help connect societal based innovation user stakeholders and universities and are a base for service provision to the Mode 2 UTT process at critical development junctures. 
Forthcoming R\&D Management

Thus, research shows that intermediaries appear to be effective structures for embracing the emergence of quadruple helix structures within regions however, research in this area is emergent. Overall Mode 2 UTT performance measurement and entities are likely to undergo further transformation as Mode 2 UTT shifts towards the more complex operating environment of the quadruple helix model.

\subsection{Theme 4: UTT and Organisational Structure}

In addition to discrete UTT entities, the literature also refers to the overall UTT organisational structure as a key theme which can be critiqued from a Quadruple Helix perspective. Ideally, in order to incorporate the inclusion of the fourth helix, organisational structure development must be integrative in nature as Mode 2 UTT from a quadruple helix perspective is a joint production effort involving co-creational and coordinated effort involving a range of stakeholders to perform complex tasks (Kotha et al., 2012).

Most UTT is embryonic and requires significant further work for successful commercialisation (Kotha et al., 2012). MacGregor et al., (2010) stress that local government need to be realistic about what entrepreneurial activities a region and stakeholders within that region can engage with. Indeed, this is evident with the emergence of the Smart Specialisation strategy which emphasises building on unique regional strengths (Carayannis and Rakhmatullin, 2014). In addition, Howells et al. (2012) identify that many industry firms have a lack of willingness to collaborate with universities despite the push for quadruple helix models. Johnston et al., (2010) identify the importance of creating an environment where there is open knowledge transfer and exchange between Mode 2 UTT stakeholders so that effective relationships can emerge as in the quadruple helix context. 
The emergence of quadruple helix societal based innovation user stakeholders will have particular implications for the role of the Technology Transfer Office (TTO) in the UTT organisational structure. Numerous studies from 2000 onwards, explored the TTO where the organisational structure (Bercovitz et al., 2001), capabilities and resources of the TTO has been found to impact the effectiveness of UTT (O'Shea et al., 2005; Siegel et al., 2007), However, the quality of TTO officers has been documented as being a barrier to UTT activities (Rothaermel et al., 2007; Siegel et al., 2007) since this can lead to missed opportunities particularly when dealing with numerous stakeholders from varying contexts. Research by Abreu and Grinevich (2013) identify that TTOs recruit a mix of employees with scientific and business backgrounds in order to have a competent and complementary pool of staff. However, in practice, smaller TTOs, often have limited resources (financial and human) which means they are lacking broad management and technical skills and knowledge of markets to effectively engage with multiple societal based innovation user stakeholders especially in a cocreational manner within the quadruple helix context (Carayannis and Campbell, 2010; Siegel et al., 2007; O’Shea et al., 2008). Such limitations can result in academics and industry questioning the competency of the TTO (Siegel et al., 2004; Klofsten et al., 2010) with a detrimental effect on commercialisation levels and success (Siegel et al., 2007).

Carayannis and Rakhmullan (2014) identify that successful innovation between quadruple helix stakeholders cannot be expected without appropriate governance structures in both regions and within institutions. They suggest the need for various new enabling roles which sponsor the infrastructure needed to help stakeholders interact. In sum, it is evident that effective support measures and appropriate organisational structures are needed to enhance quadruple helix based interactions in driving the Mode 2 UTT process (Seppo et al. 2014). 
Forthcoming R\&D Management

\subsection{Transition of UTT from a triple to quadruple helix: A Research Agenda}

It is evident from the previous discussion that Mode 2 UTT is gradually progressing from operating within a triple helix structure to a quadruple helix perspective. However, research exploring Mode 2 UTT within the increasingly complex network of quadruple helix stakeholder interactions is in its infancy (Miller et al., 2014; Wright, 2014; Ivanova, 2014) with empirical studies only beginning to emerge in the last four years. The evolving nature of UTT has meant that UTT theory and conceptualisation is still emergent and lacks an overarching theoretical position or framework (Plewa et al., 2013; Zahra et al., 2014). Moreover, the emergence of the quadruple helix interpretation of UTT presents a number of challenges to those working in the area of UTT. Since our aim in this paper is to establish a research agenda, we now identify a number of future research avenues and indicative research questions (see Table 2) which may aid future research and practice of Mode 2 UTT operating within a quadruple helix framework.

\section{Table 2 about here}

The theme of tension between basic research and commercialisation is a re-occurring theme which can be found in past literature reviews on Mode 2 UTT (Bozeman, 2000; Rothaermel et al., 2007). It is evident from existing studies that future research needs to undertake contextual based approaches to exploring this tension where, the type of university and their corresponding culture may provide unique challenges in relation to engagement with more collaborative and co-creational stakeholders emerging from the quadruple helix model. This is particularly relevant for research intensive universities whose internal promotional mechanisms may favour research publication (Van Looy et al., 2011; Hewitt-Dundas, 2012). Indeed, there is a need to explore how systems are developed to address and balance institutional need to engage more fully with quadruple helix stakeholders and individual 
Forthcoming R\&D Management

University staff preferences (Al-Mubaraki et al., 2013). It is recommended that in order to motivate academics to engage in collaborative UTT as increasingly required in the quadruple helix model, further research is needed to probe how conflict can be avoided to the mutual benefit of basic research and UTT commercialisation and to address what Etzkowitz (2003) refers to as a blurred area of study.

Studies suggests that Mode 2 UTT is increasingly becoming an iterative and messy people based process due to the co-creational and societal based innovation user aspects of the quadruple helix model (Hindle and Yencken, 2004; Lee, 2012; Payumo et al., 2012). However, there is limited understanding of the softer side of UTT as a premise for creating and managing resultant multiple collaborative UTT processes and entities (Wilson, 2012; Colapinto and Porlezza, 2012). Indeed, there is a lack of research exploring issues of trust, relationship building and tacit knowledge sharing to reflect the increasing complex 'people' based aspects of Mode 2 UTT operating within a quadruple helix ecosystem (Lee, 2012; Payumo et al., 2012). Furthermore, it is suggested that future research should explore the underlying culture, objectives and management practices of the institutions involved (e.g. the Quadruple Helix of academia, Government, industry and societal based innovation users) in order to extend knowledge and understanding of potential conflict and aid understanding of interventions on how to overcome such conflict (Li et al., 2008; Plewa et al., 2013). In addition, there is a need to recognise the important role the academic entrepreneur plays in impacting the success of quadruple helix stakeholder engagement in UTT (Miller et al., 2014). Future research needs to explore how internal mechanisms, policies and structures can be designed to motivate academics to engage more collaboratively with industry and societal based innovation users. Furthermore, there is a need for future research to determine commonalties and differences between stakeholders perceptions of more collaborative Mode 2 UTT (Siegel et al., 2004; Galbraith and McAdam, 2011) which according to Tello et al. (2011) will help define the 
Forthcoming R\&D Management

decision making process within Mode 2 UTT and aid knowledge flow towards shorter commercialisation cycle times.

Whilst the process of Mode 2 UTT has been explored in detail in the past from a triple helix perspective (Bozeman, 2000; Rothaermel et al., 2007; Guerrero and Urbano, 2010), the addition of societal based innovation users from the quadruple helix model presents the need for new performance mechanisms, processes and entities to reflect more collaborative and cocreational UTT (Miller et al., 2014). It is evident that there is a need for future studies to explore a move away from the formalised, structured, innovation push and relatively closed processes to business models and entities which are more flexible, iterative and open (Galbraith and McAdam, 2011; Colapinto and Porlezza, 2012).

In terms of UTT process flow, we propose future research on institutional mechanisms (e.g. from triple and quadruple helix constituencies) which must be in place to support and guide a more collaborative UTT process at appropriate junctures or points of need (e.g. funding stages, incentives and authorisation mechanisms) (Campbell et al., 2004; Payumo et al., 2012). Consistent with McAdam et al. (2012) it is suggested that more research on process mapping representations of Mode 2 UTT incorporating people, culture and institutional issues is needed to clarify the increasingly complex UTT processes involving participation from numerous societal based innovation user stakeholders with an increased emphasis on innovation pull. Furthermore, it is not clear, how professional practices and standards (e.g. quality) can be integrated within Mode 2 UTT to reduce process uncertainty and variability if quadruple helix stakeholders are involved in co-creating technologies (Carayannis and Rakhmullan, 2014). In order to accurately explore UTT process flow barriers and enablers, there is a need for longitudinal case based research where existing documented process maps may have been superseded with more formal tacit process activities reflecting the integration of additional 
Forthcoming R\&D Management

external stakeholders within the quadruple helix model (Campbell et al. 2004; Hindle and Yencken, 2004; Wright, 2014).

Mode 2 UTT process performance measures have mainly focused on numbers of patents, licenses, spin-outs, job creation and funding as dominant measures in the innovation push based triple helix model (Al-Mubaraki et al., 2013; Payumo et al., 2012). However, concurring with Tello et al. (2010) it is suggested that these limited UTT performance measures can instil a bounded rationality with a consequent need for further research on a wider range of potential UTT performance measures reflecting more open innovation approaches characteristic of quadruple helix structures (Perkmann and Walsh, 2007; Miller et al., 2014). With the changing policy and practice to reflect operating within quadruple helix structures, UTT performance measurements are emergent in nature with many measures not being adequately addressed such as tacit based activity costs and effectiveness, thus there is a need for more fine grained UTT performance measures (Campbell et al. 2004; Tello et al., 2010; Al-Mubaraki et al., 2013). Furthermore, as mentioned, contextual sets of performance measures (institutional and geographic) differing societal based innovation users are needed rather than assuming a best practice set can be established (Clausen and Korneliussen, 2012; Hayter, 2013) which suggests the need for more case-based research.

In relation to UTT entities, there have been sustained and prolonged calls for further research into alternative UTT channels and models (Scott, 2002; Tello et al., 2010; Hughes and Kitson, 2012). While patenting and licensing have been widely explored in the literature, their defacto status of representing UTT is again an example of bounded rationality (Tello et al., 2010) which does not account for changes in stakeholder relationships evident in the emergence of quadruple helix stakeholders. 
Forthcoming R\&D Management

Living labs and competency research centres have emerged as successful examples of intermediaries comprising of quadruple helix entities where they provide mechanisms for effective communication between quadruple helix stakeholders improving technology development and market viability in a co-creational manner (Almirall and Wareham, 2011). However, their role in UTT is lacking depth of understanding illustrating that further research into their structure, operation and performance is needed (Almirall and Wareham, 2011; Gredel et al., 2012). Furthermore, concurring with Roxas et al. (2011) and Galbraith and McAdam (2011) it is suggested there is a need for further research on the performance and effectiveness of intermediaries by taking a contextual approach where intermediaries in Mode 2 UTT are likely to vary across Universities and regions reflecting unique capabilities of societal based innovation users within the quadruple helix model.

In relation to UTT organisational structure, Etzkowitz (1998) argues that the loci of scientific knowledge has moved from the "ivory tower" towards entrepreneurial science which is a progressive interplay of cognitive opportunities, institutional rearrangements and normative change. This statement is even more significant currently given the progression to the quadruple helix model. Current UTT policy assumes interaction between quadruple helix stakeholders will naturally happen however, as Arnkil et al. (2010) notes, policy only creates conducive conditions and which may differ substantially from practice. Future research is needed therefore in order to gain a more nuanced understanding of how to create collaborative and co-ordinated environments with multiple diverse stakeholders interacting as suggested in the quadruple helix model (O'Shea et al., 2008; Kotha et al., 2012). Furthermore in terms of organisational structure the TTO faced significant challenges as a result of limited resources (Sharma et al., 2006). With the inclusion of societal based innovation user stakeholders, it is anticipated that these challenges may intensify. Consequently, further research is needed into how TTO staff attempt to develop a broad set of boundary spanning skills including marketing, 
Forthcoming R\&D Management

technical and negotiating capabilities which will bridge collaboration between quadruple helix stakeholders (Wright et al., 2009). Furthermore, future research should explore how TTOs can effectively balance the objectives of different stakeholders particularly with the emergence of additional stakeholders within a quadruple helix model (Clarysse et al., 2011; Miller et al., 2014) who can allocate expenditure and resources available for technology commercialisation activities.

\subsection{Conclusion}

Given the recent importance place on the inclusion of societal based innovation users in policy initiatives and the emergence of such in practice, the aim of this paper was to critically review Mode 2 UTT from a quadruple helix perspective and to identify key themes and future research agendas. The aim of this paper was to critically review the Mode 2 UTT literature from a quadruple helix perspective to identify future research. Given the changing role of universities in society (Lu and Etzkowitz, 2008; Urbano and Guerrero, 2013) requiring closer interaction between quadruple helix stakeholders (Wilson, 2012; RIS, 2014) and a focus on leveraging regional strengths through smart specialisation (Barca et al., 2012; Camagni and Capello, 2013), this review is timely in order to help understand the increasing complexity of Mode 2 UTT through the emergence of the quadruple helix model.

On the basis of the SLR we proposes a research agenda (Table 2) which will aid both practical and theoretical conceptualisations of the range of issues facing Mode 2 UTT operating within quadruple helix structures. It is evident that historical issues with universities involvement in UTT still remain a challenge. Accordingly, the need to engage in more open and collaborative Mode 2 UTT with quadruple helix stakeholders will not only intensify existing challenges but also presents new challenges. With the evolving nature of UTT into more collaborative 
networked stakeholder relationships consistent with the quadruple helix model there is a need for new conceptualisations and models to understand and help manage the increasing complexity of Mode 2 UTT (Perkmann and Walsh, 2007; Rothaermel et al., 2007; Urbano and Guerrero, 2013; Carayannis and Rakhmatullin, 2014). Indeed, changing organisational and contextual factors resurface past challenges which warrant further exploration and refinement in light of changes as a result of the emergence of the quadruple helix model. From the SLR, it was found that closer collaboration of societal based innovation user stakeholders identifies the need to not only re-develop Mode 2 UTT processes (Colapinto and Porlezza, 2012; Miller et al., 2014) but the need to align institutional culture, department climate, performance mechanisms and support mechanisms throughout the university to meet this goal.

It is evident that research exploring the challenges of quadruple helix models is still in its infancy (Zahra and Wright, 2011; Schoonmaker and Carayannis, 2013; Seppo et al., 2014) with existing research predominantly at the macro level reflecting a need for more longitudinal and case based research at micro levels to fully understand its complexity (Wright, 2014). The suggestions for future research agendas contribute to both theory and practice by identifying the core issues which need to be explored to ease transition into operating within a quadruple helix model. Whilst a structured SLR was undertaken, UTT is a vast and complex process (e.g. Modes 1 - 3) thus the issues identified by focussing on Mode 2 UTT are not exhaustive of the far reaching challenges a quadruple helix model poses. However, the discussion and subsequent future research agendas show how current and emergent themes in Mode 2 UTT can be further explored in terms of potential research questions at a theme and sub-theme level. The research questions are sufficiently broad as to warrant further sharpening and focusing for any given future study relating to UTT within the complex networks of stakeholder relationships in quadruple helix models. 


\section{References}

Abreu, M., Grinevich, V., Hughes, A. and Kitson, M. (2009), Knowledge Exchange between Academics and the Business, Public and Third Sectors, Centre for Business Research, University of Cambridge, Cambridge.

Abreu, M. and Grinevich, V. (2013) The nature of academic entrepreneurship in the UK: widening the focus on entrepreneurial activities. Research Policy, 42 (2), 408-422.

Almirall, E. and Wareham, J. (2011) Living Labs: Arbiters of mid- and ground-level innovation. Technology Analysis and Strategic Management 23 (1), 87-102.

Al-Mubaraki, A., Mubarak, H. and Busier, M. (2013) Business Incubation as an Economic Development Strategy: A Literature Review. International Journal of Management, 30 (1), 362-367.

Ambos, T. C., Makela, K., Birkinshaw, J. and D'este, P. (2008) When Does University Research Get Commercialized? Creating Ambidexterity in Research Institutions. Journal of Management Studies, 45, 1424-1447.

Arnkil, R., Järvensivu A., Koski, P. and Piirainen, T. (2010) Exploring Quadruple Helix Outlining user-oriented innovation models. University of Tampere, Institute for Social Research, Work Research Centre.

Asheim, B.T. and Coenen, L. (2005) Knowledge bases and regional innovation systems: comparing Nordic clusters. Research Policy, 34 (8), 1173-90.

Barca, F., McCann, P. and Rodríguez-Pose, A. (2012) The case for regional development intervention: Place-based versus place-neutral approaches. Journal of Regional Science, 52 (1), 134-152.

Becheikh, N., Landry, R. and Amara, N. (2006) Lessons from innovation empirical studies in the manufacturing sector: A systematic review of the literature from 1993-2003. Technovation, 26, 644-664.

Bercovitz, J., Feldman, M., Feller, I. and Burton, R. (2001) Organizational Structure as a Determinant of Academic Patent and Licensing Behavior: An Exploratory Study of Duke, Johns Hopkins, and Pennsylvania State Universities. Journal of Technology Transfer, 26 (12), 21-35.

Bercovitz, J. and Feldman, M. (2008) Academic Entrepreneurs: Organizational Change at the Individual Level. Organization Science, 19, 69-89.

Bercovitz, J. and M. P. Feldman. (2006) Entrepreneurial Universities and Technology Transfer: A Conceptual Framework for Understanding Knowledge-Based Economic Development. Journal of Technology Transfer, 31(1): 175-188. 
Bozeman, B. (2000) Technology Transfer and Public Policy: A Review of Research and Theory. Research Policy, 29 (4), 627-655.

Bozeman, B., Rimes, H. and Youtie, J. (2015). The evolving state-of-the-art in technology transfer research: Revisiting the contingent effectiveness model. Research Policy, 44, 34-49. Camagni, R. and Capello, R. (2013) Regional Innovation Patterns and the EU Regional Policy Reform: Toward Smart Innovation Policies. Growth and Change, 44 (2), 355-389.

Campbell, E.G., Powers, J.B., Blumenthal, D., Biles, B. (2004) Inside the Triple Helix: Technology Transfer and Commercialization In The Life Sciences. Health affairs, 23 (1), 6476.

Carayannis, E.G. and Campbell, D.F.J. (2009) “Mode 3" and "Quadruple Helix”: toward a 21st century fractal innovation ecosystem. International Journal of Technology Management, 46 (3/4), 201-234.

Carayannis, E.G., Barth, R.D. and Campbell, D.F.J. (2012) The quinuple helix innovation model: global warming as a challenge and driver for innovation. Journal of Innovation and Entrepreneurship, 1, 1-12.

Carayannis, E.G. and Campbell, D.F.G. (2014) Developed democracies versus emerging autocracies: arts, democracy, and innovation in Quadruple Helix innovation systems. Journal of Innovation and Entrepreneurship, 3, 12-24.

Carayannis, E.G. and Rakhmatullin, R. (2014) The Quadruple/Quintuple Innovation Helixes and Smart Specialisation Strategies for Sustainable and Inclusive Growth in Europe and Beyond. Journal of the Knowledge Economy, 5 (2), 212-239.

Chesbrough H. (2007) Why companies should have open business models. MIT Sloan Management Review, 48, 22-28.

Cao, Y., Zhao, L. and Chen, R. (2009) Institutional structure and incentives of technology transfer. Journal of Technology Management in China, 4 (1), 67-84.

Chesbrough H. (2011) Bringing open innovation to services. MIT Sloan Management Review, $52,85-91$.

Clarysse, B., Tartari, V. and Salter, A. (2011) The Comparative Role of TTOs and Individual Level behaviour of Academics to Explain Academic Entrepreneurship. Research Policy, 40 (8), 1084-1093.

Clausen, T. and Korneliussen, T. (2012) The relationship between entrepreneurial orientation and speed to the market: The case of incubator firms in Norway. Technovation, 32 (9-10), 560567. 
Colapinto, C. and Porlezza, C. (2012) Innovation in Creative Industries: From the Quadruple Helix Model to the Systems Theory. Journal of the Knowledge Economy, 3 (4), 343-33.

Cooke, P. (2005) Regionally asymmetric knowledge capabilities and open innovation Exploring 'Globalisation 2' - A new model of industry organisation, Research Policy, 34, 8, 1128-1149.

Djokovic, D. and Souitaris, V. (2008) Spinouts from academic institutions: a literature review with suggestions for future research. Journal of Technology Transfer, 33 (3), 225-247.

Edvardsson, B., Tronvoll, B. and Gruber, T. (2011) Expanding understanding of service exchange and value co-creation: a social construction approach, Academy of Marketing Science.Journal, 39, 2, 327-339.

Etzkowitz, H. (1998) The norms of entrepreneurial science: Cognitive effects of the new university-industry linkages. Research Policy, 27 (8), 823-833.

Etzkowitz, H. (2003) Research groups as 'quasi-firms': The invention of the entrepreneurial university. Research Policy, 32 (1), 109-121.

Etzkowitz, H. and Leydesdorff, L. (2000) The dynamics of innovation: from national systems and 'Mode 2' to a triple helix of university-industry-government relations. Research Policy, 29 (2), 109-23.

Etzkowitz, H. and Klofsten, M. (2005) The innovating region: Toward a theory of knowledge based regional development. $R \& D$ Management, 35, 243-255.

Galbraith, B. and McAdam, R. (2011) The promise and problem with open innovation. Technology Analysis and Strategic Management, 23 (1), 1-6.

Gibbons, M., Limoges, C., Nowotny, H., Schwartzman, S., Scott, P., Trow, M. (1994) The new production of knowledge: the dynamics of science and research in contemporary societies. London: Sage.

Goldfard, B. and Henrekson, M. (2003) Bottom-up versus top-down policies towards the commercialization of university intellectual property. Research Policy, 32 (4), 639-658

Gredel, D., Kramer, M. and Bend, B. (2012) Patent-based investment funds as innovation intermediaries for SMEs: In-depth analysis of reciprocal interactions, motives and fallacies. Technovation, 32 (9-10), 536-549.

Grimaldi, R., Kenney, M., Siegel, D. S. and Wright, M. (2011) 30 Years after Bayh-Dole: Reassessing Academic Entrepreneurship. Research Policy, 40 (8), 1045-1057.

Guerrero, M., Urbano, D. (2010) The development of an entrepreneurial university. The Journal of Technology Transfer, 37 (1), 43-74. 
Gunasekara, C. (2006) Reframing the Role of Universities in the Development of Regional Innovation Systems, Journal of Technology Transfer, 31, (1), 101-113.

Hayter, C.S. (2013) Conceptualizing knowledge-based entrepreneurship networks: perspectives from the literature. Small Business Economics, 41 (4), 899-911.

Hewitt-Dundas, N. (2012) Research intensity and knowledge transfer activity in UK Universities. Research Policy, 41 (2), 262-275.

Hidalgo, A. and Albors, J. (2008) Innovation management techniques and tools: a review from theory and practice. $R \& D$ Management, 38 (2), 113-27.

Hindle, K. and Yencken, J. (2004) Public Research Commercialisation, Entrepreneurship and New Technology Based Firms: An Integrated Model. Technovation, 24 (10): 793-803. HM Treasury. (2003) Lambert review of business-industry collaboration available at: http://www.hmtreasury.gov.uk/media/9/0/lambert_review_final_450.pdf (24/03/2011). Howells, J. Ramlogan, R. and Cheng, S.L. (2012) Innovation and University collaboration: paradox and complexity within the knowledge economy. Cambridge Journal of Economics, 36 (3), 703-721.

Hughes, A. and Kitson, M. (2012) Pathways to impact and the strategic role of universities: new evidence on the breadth and depth of university knowledge exchange in the UK and the factors constraining its development. Cambridge Journal of Economics, 36 (3), 723-750.

Huyghe, A., Knockaert, M., Wright, M. and Piva, E. (2014) Technology transfer offices as boundary spanners in the pre-spin-off process: the case of a hybrid model. Small Business Economics, 43, 289-307.

Ivanova, I. (2014) Quadruple Helix Systems and Symmetry: a Step towards Helix Innovation System Classification. Journal of the Knowledge Economy, 5 (2), 357-369.

Johnston, L., Robinson, S. and Lockett, N. (2010) Recognising 'open innovation' in HEIindustry interaction for knowledge transfer and exchange. International Journal of Entrepreneurial Behaviour and Research, 16 (6), 540-60.

Kenney, M. and Mowery, D. (2014) Public Universities and Regional Development: Insights from the University of California System. Palo Alto, CA, Stanford University Press.

Klofsten, M., Heydebreck, P., and Jones-Evans, D. (2010) Transferring good practice beyond organizational borders: Lessons from transferring an entrepreneurship programme. Regional Studies, 44 (6), 791-799. 
Kotha, R., George, G. and Srikanth, K. (2012) Bridging the Mutual Knowledge Gap: Coordination and the Commercialisation of University Science. Academy of Management Journal, 56 (2), 498-524.

Larsen, M.T. (2011) The implications of academic enterprise for public science: An overview of the empirical evidence. Research Policy, 40 (1), 6-19.

Lee, P. (2012) Transcending the Tacit Dimension: Patents, Relationships, and Organizational Integration in Technology Transfer. California Law Review, 100 (9), 1035-1057

Leydesdorff, L. (2011) The Triple Helix, Quadruple Helix, and an N-Tuple of Helices: Explanatory Models for Analyzing the Knowledge-Based Economy? Journal of the Knowledge Economy, 3 (1), 25-35.

Li, Y., Yi, L., Yi, D. and Li, M. (2008) Entrepreneurial orientation, strategic flexibilities and indigenous firm innovation in transitional China. International Journal of Technology Management, 41 (1), 223-246.

Link, A. N. and Siegel, D. S. (2005) Generating science-based growth: an econometric analysis of the impact of organizational incentives on university-industry technology transfer. The European Journal of Finance, 11, 169-181.

Lipinski, J., Lester, D.L. and Nicholls, J. (2013) Promoting Social Entrepreneurship: Harnessing Experiential Learning with Technology Transfer to Create Knowledge Based Opportunities. Journal of Applied Business Research, 29 (2), 597-606.

Lu, L. and Etzkowitz, H. (2008) Strategic challenges for creating knowledge-based innovation in China: transforming triple helix university-government-industry relations. Journal of Technology Management in China, 3 (1), 5-11.

MacGregor, S.P. Marques-Gou, P. and Simon-Villar, A. (2010) Gauging Readiness for the Quadruple Helix: A Study of 16 European Organisations. Journal of the Knowledge Economy, 1 (3), 173-190.

Markman, G.D., Siegel, D.S. and Wright, M. (2008) Research and Technology Commercialization. Journal of Management Studies, 45, 1401-1423.

McAdam, R., Miller, K., McAdam, M. and Teague, S. (2012) The development of University Technology Transfer stakeholder relationships at a regional level: lessons for the future. Technovation, 32 (1), 57-67.

Miles, M.B. and Huberman, M. (1994) Qualitative Data Analysis: An expanded Sourcebook. Sage: London.

Miller, K., McAdam, M. and McAdam, R. (2014) The University Business Model: Evolution and Emergence from a Stakeholder Perspective. R\&D Management, 44, 265-287. 
Forthcoming R\&D Management

Mitev, N. and Venters, W. (2009) Reflexive Evaluation of an Academic-Industry Research Collaboration: Can Mode 2 Management Research be Achieved? The Journal of Management Studies, 46, (5), 733-749.

O’Shea, R.P, Allen, T. J., Chevalier, A. and Roche, F. (2005) Entrepreneurial orientation, technology transfer and spinoff performance of U.S. universities. Research Policy, 34, 994 1009.

O'Shea, R.P., Chugh, H. and Allen, T.J. (2008) Determinants and consequences of university spinoff activity: A conceptual framework. International Journal of Technology Transfer, 33 (6), 653-666.

Payumo, J., Gang, Z., Pulumbarit, E., Jones, K., Maredia, K. and Grimes, H. (2012) Managing intellectual property and technology commercialization: Comparison and analysis of practices, success stories and lessons learned from public research universities in developing Asia. Innovation Management, Policy and Practice, 14 (4), 478-494.

Perkmann, M. and Walsh, K. (2007) University-industry relationships and open innovation: towards a research agenda. International Journal of Management Reviews, 9 (4), 259-280.

Perkmann, M., Tartari, V., McKelvey, M., Autio, E., Brostrom, A., D’Este, P., Fini, R., Geuna, A., Grimaldi, R., Hughes,A., Krabel, S., Kitson, M., Llerena, P., Lissoni, F., Salter, A. and Sobrero, M. (2013) Academic engagement and commercialisation: A review of the literature on university Industry relations. Research Policy, 42 (2), 423-442.

Pittaway, L. and Cope, J. (2007) Simulating Entrepreneurial Learning Integrating Experiential and Collaborative Approaches to Learning. Management Learning, 38 (2), 211-233.

Plewa, C., Rampersad, G., Johnson, C.R., Baaken, T., MacPherson, G. and Korff, N. (2013). The evolution of university-industry linkages-A framework. Journal of Engineering and Technology Management, 30 (1), 21-44.

Prajapati, V., Tripathy, S. and Dureja, H. (2013) Product lifecycle management through patents and regulatory strategies. Journal of Medical Marketing, 13 (3), 171-180.

Rademakers, M., 2005. Corporate Universities, Driving Force of Knowledge Innovation. The Journal of Workplace Learning 17 (1), 130-136.

RIS (2014) National/Regional Innovation Strategies for Smart Specialisation. Cohesion Policy 2014-2020, European Commission. Available online: http://ec.europa.eu/regional_policy/sources/docgener/informat/2014/smart_specialisation_en. pdf (accessed 10/12/2014).

Rothaermel, F.T., Agung, S.D. and Jiang, L. (2007) University entrepreneurship: A taxonomy of the literature. Industrial and Corporate Change, 16 (4), 691-791. 
Roxas, S.A., Piroli, G. and Sorrentino, M. (2011) Efficiency and evaluation analysis of a network of technology transfer brokers. Technology analysis and strategic management, $\mathbf{2 3}$ (1), 7-24.

Savva, N. and Scholtes, S. (2014) Opt-Out Options in New Product Co-development Partnerships. Production and Operations Management, 23, (8), 1370-1386.

Schoonmaker, M.G. and Carayannis, E.G. (2013) Mode 3: A Poposed Classification Scheme for the Knowledge Economy and Society. Journal of the Knowledge Economy, 4 (4), 56-577. Schuurman, D., Lievens, B., De Marez, L. \& Ballon, P. 2012, "Innovation from user experience in Living Labs: revisiting the 'innovation factory'-concept with a panel-based and user-centered approach", The International Society for Professional Innovation Management (ISPIM), Manchester, 1-11.

Scott, S. (2002) Selling university technology: Patterns from MIT. Management Science, 48 (1), 122-137.

Seppo, M., Roigas, K. and Varblane, U. (2014) Governmental Support Measures for University-Industry Cooperation - Comparative View in Europe. Journal of the Knowledge Economy, 5 (2), 388-408.

Siegel, D. S., Veugelers, R. and Wright, M. (2007) Technology Transfer Offices and Commercialization of University Intellectual Property: Performance and Policy Implications. Oxford Review of Economic Policy, 23 (4), 640-660.

Siegel, D.S., Waldman, D.D., Atwater, L.E. and Link, A.N. (2004) Toward a model of the effective transfer of scientific knowledge from academicians to practitioners: qualitative evidence from the commercialization of university technologies. Journal of Engineering and Technology Management, 21, 115-42.

Starkey, K. and Madden, P. (2001) Bridging the Relevance Gap: Aligning Stakeholders in the Future of Management Research. British Journal of Management, 12, 3-26.

Stokes, D.D. (1997) Pasteur's Quadrant: basic science and technological innovation. The Brookings Institution, Washington.

Swan, J., Bresnen, M., Robertson, M., Newell, S. and Dopson, S. (2010) When Policy meets Practice: Colliding Logics and the Challenges of 'Mode 2' Initiatives in the Translation of Academic Knowledge, Organization Studies, 31 (9), 1311.

Tello, S., Latham, S. and Kijewski, V. (2011) Assessing differences between technology transfer officers and institutions in the decision to commercialise new technologies. International Journal of Technology Transfer and Commercialisation, 10 (1), 93-111. 
Thorpe, R., Holt, R., MacPherson, A. and Pittaway, L. (2005) Using knowledge within small and medium-sized firms: A systematic review of the evidence. International Journal of Management Reviews, 7 (4), 257-281.

Tödtling, F. and Trippl, M. (2005) One size fits all? Towards a differentiated regional innovation policy approach. Research Policy, 34 (1), 1023-1209.

Tranfield, D., Denyer, D. and Smart, P. (2003) Towards a Methodology for Developing Evidence-Informed Management Knowledge by Means of Systematic Review. British Journal of Management, 14 (3), 207-222.

Tranfield, D. and Starkey, K. (1998) The nature, social organisation and promotion of management research: Towards policy. British Journal of Management, 9 (4), 341-353.

Urbano, D. and Guerrero, M. (2013) Entrepreneurial Universities: Socioeconomic Impacts of Academic Entrepreneurship in a European Context. Economic Development Quarterly, 27 (1), 40-55.

Van Looy, B., Landoni, P., Callaert, J., van Pottelsberghe, B., Sapsalis, E. and Debackere, K. (2011) Entrepreneurial effectiveness of European universities: An empirical assessment of antecedents and trade-offs. Research Policy, 40 (4), 553-564.

Wilson, T. (2012) A Review of Business-Industry Collaboration. London: Department for Business, Innovation and Skills. Available https://www.gov.uk/government/uploads/system/uploads/attachment_data/file/32383/12-610wilson-review-business-university-collaboration.pdf (accessed 18/12/2014).

Wright, M., Piva, E., Mosey, S. and Lockett, A. (2009) Academic entrepreneurship and business schools, Journal of Technology Transfer, 34, 560-587.

Wright, M. (2014) Academic Entrepreneurship, Technology Transfer and Society: Where Next? Journal of Technology Transfer, 39, 322-334.

Zahra, S.A. and Wright, M. (2011) Entrepreneurship's next act. Academy of Management Perspectives, 25 (4), 67-83. 
Zahra, S.A. Wright, M. and Abdelgawad, G. (2014) Contextualisation and Advancement of Entrepreneurship Research. International Small Business Journal, 32, 479-500.

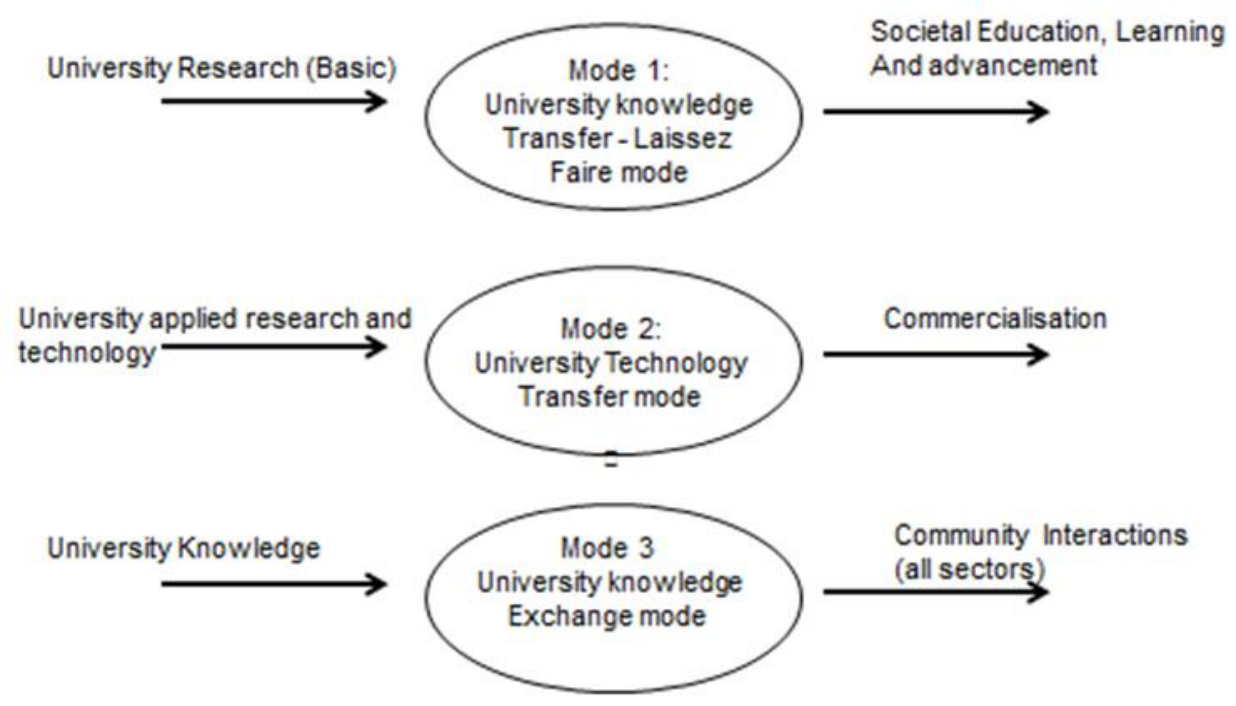

Figure 1: Knowledge Production Modes and University Knowledge Transfer Source: Gibbons et al., (1994).

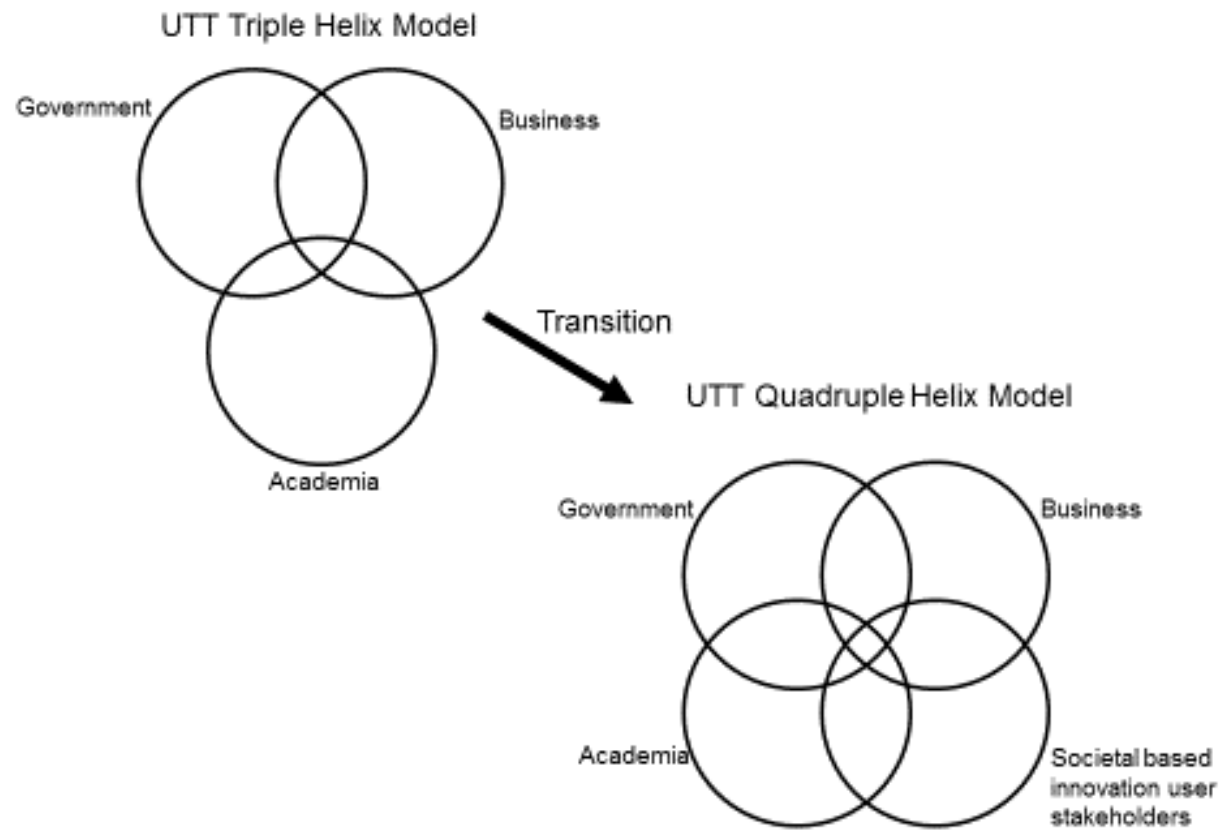

Figure 2: Triple and Quadruple Helix UTT

Source: Adapted from Carayannis and Campbell (2009) 


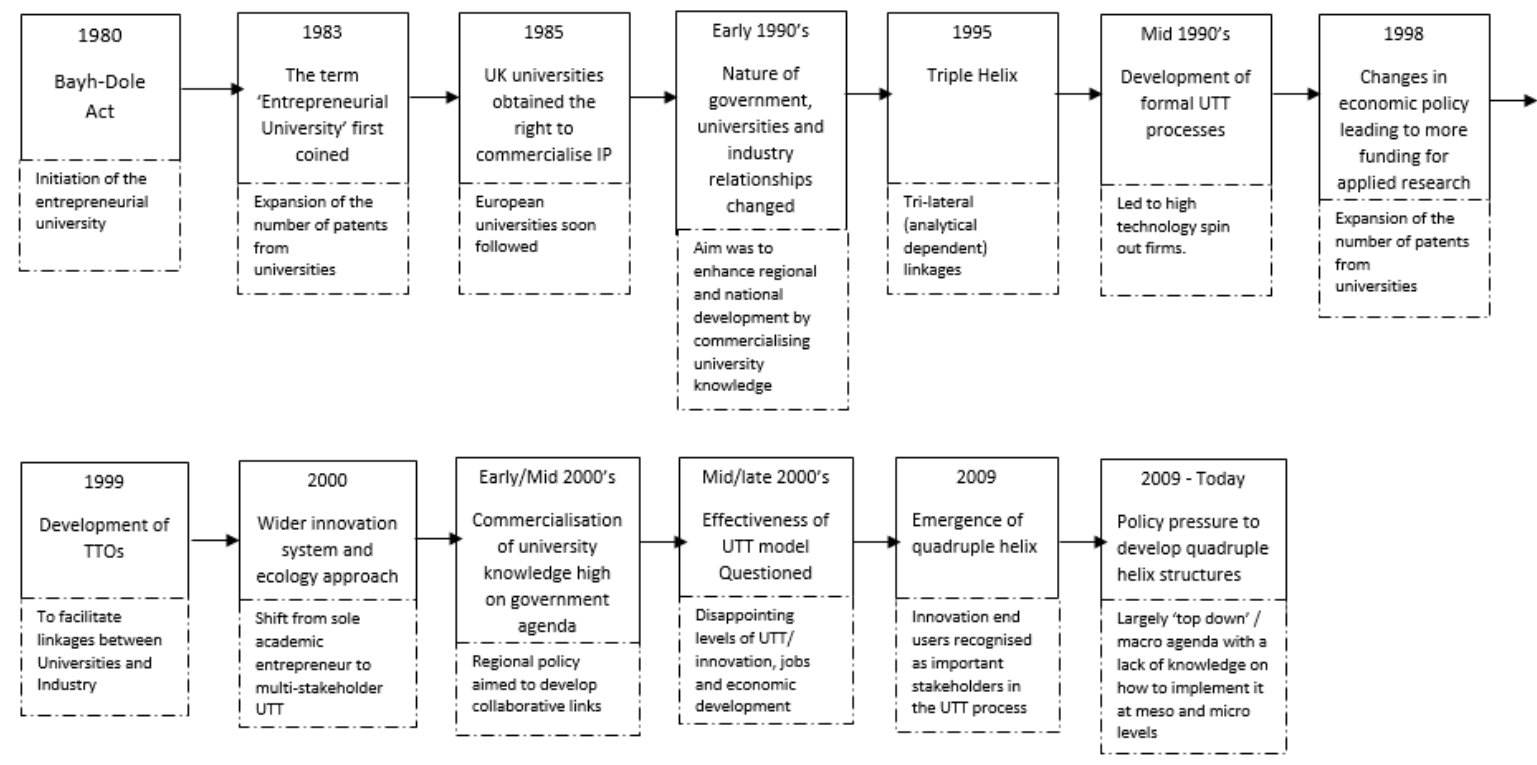

Figure 3: Trajectory of Entrepreneurial University and UTT Stakeholder Relationship

Table 1: Papers Extracted from Systematic Literature Review

\begin{tabular}{|l|l|l|}
\hline & ABI/ProQuest & Business Source Premier \\
\hline $\begin{array}{l}\text { Technology and } \\
\text { commercialisation } \\
\text { universities }\end{array}$ & 13 & 41 \\
\hline $\begin{array}{l}\text { Technology ased } \\
\text { entrepreneurship and } \\
\text { universities }\end{array}$ & 6 & 6 \\
\hline $\begin{array}{l}\text { Academic enterprise and } \\
\text { universities and universities }\end{array}$ & 37 & 5 \\
\hline Triple helix and & 10 & 22 \\
\hline $\begin{array}{l}\text { Quadruple helix } \\
\text { universities an }\end{array}$ & 75 & 76 \\
\hline Total & \\
\hline
\end{tabular}


Forthcoming R\&D Management

Table 2: Agenda for Future Research

\begin{tabular}{|c|c|c|c|}
\hline Theme & Sub theme & Example Research Questions & References \\
\hline $\begin{array}{l}\text { 1. Tension between basic } \\
\text { research and } \\
\text { commercialisation }\end{array}$ & $\begin{array}{l}\text { Research versus Publishing } \\
\text { Conflicts } \\
\text { Polarities of research and UTT } \\
\text { Negative outcomes of Bayh-Dole } \\
\text { Act }\end{array}$ & $\begin{array}{l}\text { What mechanisms (e.g. incentives, training) can help balance basic } \\
\text { research and co-creational technology commercialisation with industry } \\
\text { and societal based end users? } \\
\text { How do contextual issues (e.g. University type and culture) impact } \\
\text { collaborative research activities with quadruple helix stakeholders? } \\
\text { What environmental changes are needed to achieve Pasteur's } \\
\text { quadrant? } \\
\text { What directions should future enabling legislation take in order to } \\
\text { facilitate collaborative UTT with quadruple helix stakeholders? }\end{array}$ & $\begin{array}{l}\text { Bozeman (2000); Etzkowitz and Leydesdorff (2000); } \\
\text { Campbell et al. (2004); Link and Siegel (2005); Bercovitz } \\
\text { and Feldman, (2008); Perkmann and Walsh, (2007); O’Shea } \\
\text { et al. (2008); Larsen (2011); Hughes and Kitson (2012); Al } \\
\text { Murabaki et al. (2013) } \\
\text { MacGregor et al. (2010); Daskalopoulou et al. (2010); Van } \\
\text { Looy (2011); Hewitt-Dunda, (2012); Galbraith and } \\
\text { McAdam (2013); Ivanova (2014) } \\
\text { Larsen (2011); Clausen and Korneliusse (2012) } \\
\text { Sharma et al. (2006); Bercovitz and Feldman (2006); } \\
\text { Perkmann and Walsh (2007); Grimaldi (2007); Miller et al. } \\
\text { (2014) }\end{array}$ \\
\hline $\begin{array}{l}\text { 2. Developing Stakeholder } \\
\text { Relationships }\end{array}$ & People based aspects of UTT & $\begin{array}{l}\text { How can 'softer' infrastructures and social integration mechanisms be } \\
\text { set up to enhance relationship building and knowledge transfer } \\
\text { between quadruple helix stakeholders? } \\
\text { How can perceptions and objectives of quadruple helix stakeholders be } \\
\text { aligned to reduce conflict during UTT? } \\
\text { How do contextual factors influence university engagement with } \\
\text { quadruple helix stakeholders? } \\
\text { What internal mechanisms, policies and structures will motivate } \\
\text { academics to engage more with industry and societal based end users } \\
\text { (e.g. career stage, incentives, department climate)? }\end{array}$ & $\begin{array}{l}\text { Colapinto and Porlezza (2012); Lee, (2012); Payumo et al. } \\
\text { (2012); Miller et al. (2015) } \\
\text { Hidalgo and Albors (2008); Plewa et al. (2012); McAdam et } \\
\text { al. 2012; Miller et al. (2014) } \\
\text { MacGregor et al. (2010); Clausen and Korneliussen (2012); } \\
\text { Galbraith and McAdam (2013); Miller et al. (2014); Ivanova } \\
\text { (2014); McAdam et al. (2015) } \\
\text { Markmann et al. (2008); Perkmann and Walsh (2007); } \\
\text { Kotha et al. (2012); Perkmann et al. (2013); Urbano and } \\
\text { Guerrero (2013) }\end{array}$ \\
\hline
\end{tabular}




\begin{tabular}{|c|c|c|c|}
\hline Theme & Sub theme & Further Research Areas & References \\
\hline $\begin{array}{l}\text { 3. UTT Performance } \\
\text { Measures and Entities }\end{array}$ & $\begin{array}{l}\text { UTT process flow dynamics } \\
\text { UTT process performance } \\
\text { measurement. }\end{array}$ & $\begin{array}{l}\text { Does the integration of end users in the UTT process enhance or reduce } \\
\text { uncertainty? } \\
\text { How do UTT processes interact with quadruple helix stakeholders at key } \\
\text { process junctures? } \\
\text { Will performance measures be able to balance the needs and priorities } \\
\text { of each quadruple helix stakeholder? } \\
\text { How can tacit-based activity costs and effectiveness or quadruple helix } \\
\text { stakeholder collaboration during UTT be measured? } \\
\text { How do institutional and geographic factors impact upon quadruple } \\
\text { helix stakeholder engagement during Mode } 2 \text { UTT? } \\
\text { What models of UTT allow more effective engagement with quadruple } \\
\text { helix stakeholders overcoming IP issues and conflicting objectives? } \\
\text { What type of intermediaries at core UTT junctures are needed to } \\
\text { increase quadruple helix stakeholder engagement? }\end{array}$ & $\begin{array}{l}\text { Tello et al. (2011); Plewa et al. (2013); Wright (2014); } \\
\text { Zahra et al. (2014); Miller et al. (2014); Seppo et al. (2014) } \\
\text { Almirall and Wareham (2011); Arnkil et al. (2010); Lee } \\
\text { (2012); Perkmann et al.(2013) Carayannis and Campbell } \\
\text { (2014) } \\
\text { Grimaldi et al. (2011); McAdam et al. (2015); Clausen and } \\
\text { Korneliussen (2012); Hayter (2013);Ivanova (2014) } \\
\text { Arnkil et al. (2010); Mac Gregor et al. (2010); Larsen } \\
\text { (2011); Galbraith and McAdam (2011); Miller et al. (2014); } \\
\text { Etzkowitz (2003); Hindle and Yencken (2004) Roxas et al., } \\
\text { 2011; Almirall and Wareham (2011);Gredel et al. 2012; Lee } \\
\text { (2012) }\end{array}$ \\
\hline $\begin{array}{l}\text { 4. UTT and organisational } \\
\text { structure }\end{array}$ & $\begin{array}{l}\text { Institutional and regional } \\
\text { considerations }\end{array}$ & $\begin{array}{l}\text { Are structural and institutional arrangements conducive to } \\
\text { collaborative open innovation processes with quadruple helix } \\
\text { stakeholders? }\end{array}$ & $\begin{array}{l}\text { Siegel et al. (2007); O'Shea et al. (2008); Carayannis and } \\
\text { Campbell, (2010); Van Looy (2011); Clausen and Korneliusse } \\
\text { (2012); McAdam et al. (2012); Abreu and Grinevich (2013); } \\
\text { Hewitt-Dundas (2012); Wright (2014); Zahra et al (2014); } \\
\text { Miller et al. (2014) } \\
\text { MacGregor et al. (2010); Hayter (2013); Hughes and Kitson } \\
\text { (2012); Perkmann et al. (2013); Ivanova (2014); }\end{array}$ \\
\hline
\end{tabular}


Forthcoming R\&D Management

\begin{tabular}{|l|l|l|l|}
\hline & & $\begin{array}{l}\text { What type of enabling governance mechanisms enhance quadruple } \\
\text { helix stakeholder interactions? } \\
\text { How can TTOs support and enhance quadruple helix collaboration for } \\
\text { UTT? }\end{array}$ & $\begin{array}{l}\text { Miller et al. (2014); Carayannis and Rakhmullan (2014); } \\
\text { Seppo et al. (2014) } \\
\text { O'Shea et al. (2005); Siegel et al. (2007); Rothaermel et al. } \\
\text { (2007); Klofsten et al. (2010); Carayannis and Campbell } \\
\text { (2010); Abreu and Grinevich (2013) }\end{array}$ \\
\hline
\end{tabular}


Forthcoming R\&D Management 
Forthcoming R\&D Management 
Forthcoming R\&D Management 